\title{
LA APLICABILIDAD DEL DERECHO INTERNACIONAL POR TRIBUNALES CHILENOS PARA INTERPRETAR LA LEY N $^{\circ} 20.357^{*}$
}

\section{Claudia Cárdenas Aravena**}

RESUMEN: El artículo explica cómo es que los criterios de interpretación mayoritariamente considerados vinculantes para la interpretación judicial de toda ley penal en Chile llevan a entender que el derecho internacional ha de jugar un rol relevante en la interpretación de la Ley $\mathrm{N}^{\circ}$ 20.357, que tipifica los crímenes de guerra, de lesa humanidad y el genocidio en el Derecho chileno; y cómo es que el principio de legalidad no es, a priori, un obstáculo para ello. Para eso, parte refiriéndose al principio de legalidad con los efectos que se le reconocen en el derecho continental y su rol en la interpretación de las leyes penales; para seguir con una revisión de los distintos criterios de interpretación legal contenidos en el Código Civil chileno, con especial referencia a la Ley $\mathrm{N}^{\circ} 20.357$; y terminar con una referencia al modo en que un ordenamiento jurídico comparable, como es el alemán, resuelve el asunto.

PALABRAS CLAVE: Ley $\mathrm{N}^{\circ} 20.357$ (Chile) - interpretación de la ley penal - aplicabilidad del derecho internacional - juzgamiento de crímenes internacionales en Chile - principio de legalidad en el sistema continental.

\section{THE APPLICABILITY OF INTERNATIONAL LAW BY CHILEAN COURTS FOR THE INTERPRETATION OF LAW $\mathbf{N}^{\circ} \mathbf{2 0 . 3 5 7}$}

ABSTRACT: This article explains how the interpretation criteria that are commonly considered binding for the judicial interpretation of Chilean criminal law leads to understand that international law has a relevant role to play in the interpretation of the $\mathrm{N}^{\circ} 20.357$ Law, which punishes war crimes, crimes against humanity and genocide in Chilean law; and

Este trabajo cuenta con el patrocinio de FONDECYT (proyecto $\mathrm{N}^{\circ} 1120097$ ).

Fecha de recepción: 18 de marzo de 2013.

Fecha de aceptación: 30 de agosto de 2013.

** Licenciada en Ciencias Jurídicas y Sociales, Magíster y Doctora en Derecho, Facultad de Derecho de la Universidad de Chile. Correo electrónico: cardenascl@yahoo.de 
how the legality principle does not, a priori, collide with that relevant role. In order to arrive to this explanation, the text begins with a reference to the legality principle, considering the effects that are normally attributed to it in civil law countries, and its role in the interpretation of criminal prescriptions. It continues reviewing the different criteria of legal interpretation contained in the Chilean civil code, with special reference to the $\mathrm{N}^{\circ} 20.357$ Law; and it ends referring to the way in which a comparable criminal order, as the German criminal order, resolves the matter.

KEY WORDS: $\mathrm{N}^{\circ} 20.357$ Law - interpretation in criminal law - applicability of international law - judgment of international crimes in Chile - legality principle in the continental system.

Sumario: Introducción. 1. El principio de legalidad y la interpretación de leyes penales considerando el derecho internacional. 1.1 El principio de legalidad en Chile. 1.2 Las leyes penales en blanco con reenvío al derecho internacional. 1.3 La interpretación de las leyes penales y el principio de legalidad. 2. Los criterios de interpretación de las leyes penales usualmente reconocidos. 2.1 Criterios vinculantes. 2.1.1 El sentido literal. 2.1.2 El contexto de la ley. 2.2 Criterio supletorio: la finalidad de la ley. 2.2.1 Finalidad de la ley manifestada en si misma. 2.2.2 Finalidad de la ley manifestada en la historia fidedigna de su establecimiento. 2.3 Criterios a aplicar en caso de inviabilidad de los anteriores. 3. El ejemplo alemán y la interpretación favorable al derecho internacional (Völkerrechtsfreundliche Auslegung). Conclusiones

\section{I) INTRODUCCIÓN}

En general, la relación entre el derecho internacional y el derecho penal interno no es de las más fáciles, en un sistema continental como el nuestro, en donde dentro de las primeras nociones de formación jurídicopenal se entrega la máxima de que solo la ley es fuente directa del derecho penal ${ }^{1}$, junto a la que suele albergarse la suspicacia de que cualquier papel

En la doctrina nacional, a saber, Cury Urzúa, Enrique (2005). Derecho Penal, parte general. Santiago, Ediciones Universidad Católica de Chile, pp. 169 y ss.; Novoa Monreal, Eduardo (2005). Curso de derecho penal chileno. Parte general, tomo I. Santiago, Editorial Jurídica de Chile, $3^{a}$ ed., pp. 111 y s.; Politoff Lifschitz, Sergio, Matus Acuña, Jean Pierre y Ramírez Guzmán, María Cecilia (2003). Lecciones de derecho penal chileno, parte general, Santiago, Editorial Jurídica de Chile, $2^{\mathrm{a}}$ ed. actualizada, pp. 93 y ss. 
que vaya a jugar el derecho internacional - con su sistema de fuentes que incluye la costumbre ${ }^{2}$ - deba ser mirada con cuidado ${ }^{3}$.

Un ejemplo elocuente de esta tendencia a evitar el recurso explícito al derecho internacional para la interpretación de la ley penal es la sentencia del Tribunal Constitucional referido a la piratería (artículo 434 del Código Penal $)^{4}$. Se discutía allí si acaso la voz piratería era suficiente descripción de la conducta punible en al artículo 434 del Código Penal chileno. El Tribunal llegó a la conclusión de que sí lo era, explicando al efecto cómo se ha de llenar de contenido el término. Resulta profundamente llamativo que lo haya hecho con prescindencia absoluta del derecho internacional, que ya desde antes de su tipificación en el Código Penal chileno regula a la piratería, para determinar el significado del término. Es decir, se hizo caso omiso del derecho internacional a la hora de interpretar esa disposición penal, a pesar de los insoslayables orígenes y trascendencia internacional del delito ${ }^{5}$, que fuera reconocida claramente incluso por juristas chilenos de generaciones anteriores, como los redactores del Código Orgánico de Tribunales, al reconocerle competencia extraterritorial

2 Se considera mayoritariamente que el artículo 38 párrafo 1 del Estatuto de la Corte Internacional de Justicia recoge las que se reconocen como fuentes formales del derecho internacional, que incluyen "a. las convenciones internacionales, sean generales o particulares, que establecen reglas expresamente reconocidas por los Estados litigantes; b. la costumbre internacional como prueba de una práctica generalmente aceptada como derecho; c. los principios generales de derecho reconocidos por las naciones civilizadas; d. las decisiones judiciales y las doctrinas de los publicistas de mayor competencia de las distintas naciones, como medio auxiliar para la determinación de las reglas de derecho, sin perjuicio de lo dispuesto en el Artículo 59". Disponible en http://www.un.org/spanish/aboutun/icjstat.htm [fecha de visita 8 de marzo de 2013].

3 Baste considerar el tiempo que ha debido transcurrir para que se vayan abriendo camino las referencias al derecho internacional en las denominadas "causas de derechos humanos". Ejemplos connotados de esta tendencia son las sentencias: Corte Suprema. 9 de septiembre de 1998. Rol 469-98. "Desaparición de Pedro Poblete Córdova". Fallos del Mes, № 478, pp. 1760-1769 (considerandos 9 y 10); Corte Suprema. 13 de diciembre de 2006. Rol No 559-2004. "Homicidios de Hugo Vásquez Martínez y Mario Superby Jeldres" (caso Molco). Estudios Constitucionales, ańo $5 \mathrm{~N}^{\circ}$ 1, pp. 533-549 (considerando 27); Corte Suprema. 25 de septiembre de 2008. Rol No 4.662-07. "Episodio Liquiñe" (2008). Disponible en http://www.memoriaviva.com/fallos.htm [fecha de visita 8 de marzo de 2013] (considerando 6; Corte Suprema. 4 de agosto de 2010. Rol No 7089-09. Homicidio calificado de Rafael Vergara Toledo y el homicidio simple de Eduardo Vergara Toledo”. Disponible en http://www.ddhh.gov.cl/fallosagosto2010.html [fecha de visita 8 de marzo de 2013] (considerandos 2 y 3$)$.

4 Tribunal Constitucional. 30 de marzo de 2007. Rol 549-06, "Requerimiento de inaplicabilidad por inconstitucionalidad presentado por el Juez Presidente de la Segunda Sala del Tribunal Oral en lo Penal de Concepción, respecto del artículo 434 del Código Penal, en la causa RIT No 130-2006, sobre piratería, seguida ante el tribunal del juicio oral en lo Penal de Concepción”. Disponible en http://www.tribunalconstitucional.cl/wp/ver.php?id=124 [fecha de visita 8 de marzo de 2013].

5 Respecto del derecho penal internacional y el derecho penal de trascendencia internacional, Werle, Gerhard (2011). Tratado de derecho penal internacional. 2a ed. Valencia, Tirant lo Blanch, pp. 77 y ss. y 88 y ss. 
al Estado de Chile para juzgar la piratería prescindiendo de cualquier condición, reconociendo así a su respecto un verdadero principio de universalidad (artículo $6 \mathrm{~N}^{\circ} 7$ del Código Orgánico de Tribunales) ${ }^{6}$. Así las cosas, parece pertinente dedicar un esfuerzo a aclarar el rol que ha de jugar el derecho internacional de cara a una futura aplicación de la Ley $\mathrm{N}^{\circ}$ 20.357, habida cuenta de que la competencia para los delitos que allí se tipifican sigue las reglas generales ${ }^{7}$, por lo que no se puede descansar en que vaya a existir una especialización en la materia por parte de quienes en su momento deban aplicarla.

En el texto siguiente se pretende explicar cómo es que, echando mano de los criterios mayoritariamente reconocidos para la interpretación de la ley penal chilena, ha de llegarse a la conclusión de que -al menos en el caso de la Ley $\mathrm{N}^{\circ}$ 20.357, que tipifica en el derecho interno chileno los delitos y crímenes de guerra, los crímenes de lesa humanidad y el genocidio- el recurso al derecho internacional para la interpretación de la ley penal chilena no solo es posible, sino incluso necesario.

No se pretende, empero, realizar una interpretación de cada uno de los preceptos de la ley (lo que resultaría por lo demás impracticable en este formato), sino que más bien se pretende fundamentar cómo es que ya en un análisis general se encuentran argumentos para acudir al derecho internacional al interpretar esta ley.

\section{1) INTERPRETACIÓN CONFORME AL DERECHO INTERNACIONAL Y PRINCIPIO DE LEGALIDAD PENAL}

Un primer tema a despejar es si existe -en principio- alguna colisión entre la interpretación de una ley penal chilena conforme al derecho internacional y el principio de legalidad, con los efectos que se le atribuyen

6 Sobre el principio de universalidad o de jurisdicción universal, explicando su fuente internacional, Bassiouni, M. Cherif (2001). "Universal jurisdiction for international crimes: Historical perspectives and contemporary practice", Virginia Journal of International Law 42, pp. 81 y ss.: Benavides, Luis (2001). "The Universal Jurisdiction Principle: nature and scope”. 1 Anuario Mexicano de Derecho Internacional, pp. 19 y ss.; Inazumi, Mitsue (2005). Universal Jurisdiction in Modern International Law: Expansion of National Jurisdiction for Prosecuting Serious Crimes under International Law. Antwerpen, Intersentia, 269 pp.; MaCedo, Stephen (2006). Universal jurisdiction. Pennsylvania, University of Pennsylvania Press, 383 pp.

7 Solo existe una disposición relativa al Ministerio Público. El artículo 43 de la Ley $N^{\circ}$ 20.357 modificó el 19 de la Ley Orgánica Constitucional del Ministerio Público No 19.640, disponible en http://www.leychile.cl/Navegar?idNorma=145437 [fecha de visita 8 de marzo de 2013], estableciendo que "[s]e entenderá, especialmente, que resulta necesaria [la] designación [de un Fiscal Regional para hacerse cargo del ejercicio de la acción penal pública y la protección de las víctimas y testigos], tratándose de investigaciones por delitos de lesa humanidad y genocidio". 
en el derecho chileno ${ }^{8}$. Para ello, se comenzará con una alusión general al principio de legalidad en Chile y su consagración positiva, siguiendo con una referencia particular a las leyes penales en blanco con reenvío al derecho internacional y finalizando con un breve examen de la relación general entre el principio de legalidad y la interpretación de la ley penal.

\section{1) EL PRINCIPIO DE LEGALIDAD EN CHILE}

Sabido es que el principio de legalidad penal, en un sistema de derecho continental como el nuestro, implica una limitación en dos aspectos: primero, restringe las fuentes mediante las cuales se puede establecer, describiéndolas, conductas punibles; y, segundo, limita las fuentes mediante las cuales se pueden establecer la naturaleza, mínimo y máximo de las penas que corresponde aplicar en caso de la comisión de las antedichas conductas punibles?.

Mediante la Ley $\mathrm{N}^{\circ} 20.357$ se cumple cabalmente con esa limitación formal para los crímenes de guerra, los crímenes de lesa humanidad y en genocidio.

Las fuentes positivas del principio de legalidad las encontramos en el artículo $19 \mathrm{~N}^{\circ} 3$ de la Constitución Política de la República, el que dispone, en su inciso 9, que "ninguna ley podrá establecer penas sin que la conducta que se sanciona esté expresamente descrita en ella”, reconociendo de este modo el principio de legalidad en su manifestación lex certa como parte de nuestro ordenamiento jurídico. La exigencia de lex praevia se encuentra en el inciso 8 del artículo $19 \mathrm{~N}^{\circ} 3$ de la Constitución: [n] ingún delito se castigará con otra pena que la que señale una ley promulgada con anterioridad a su perpetración, a menos que una nueva ley favorezca al afectado". También se suele citar como fuente formal del principio de legalidad en el derecho chileno al artículo 1 del Código Penal: "[e] s delito toda acción u omisión voluntaria penada por la ley". Lo anterior, unido a la definición de ley del artículo 1 del Código Civil, conforme a la cual se requiere que la voluntad soberana esté expresada "en la forma prescrita por la Constitución” explicita el mandato de lex scripta.

Aparte de estas fuentes de derecho interno, nos vinculan asimismo el principio de legalidad como principio general de derecho y los tratados de derechos humanos, que prevén la legalidad como una garantía para el individuo. Con todo, para los efectos de este análisis puede constatarse

\footnotetext{
8 Sobre el principio de legalidad en el derecho internacional, Deffert, Dietmar (2011). Strafgesetzlichkeit als völkerstrafrechtliches Legitimationsprinzip, Frankfurt am Main, Peter Lang, 249 pp., en particular pp. 61 y ss.

9 A saber, en doctrina nacional, Matus Acuña, Jean Pierre (2012). La ley penal y su interpretación. 2a ed., Santiago: Editorial Metropolitana, p. 66; Politoff/Matus/Ramírez (2003) 93 y ss. Cury (2005) 165 y ss.
} 
que estos últimos no contienen un mandato de lex scripta. En un caso se hace expresa referencia al derecho internacional junto al nacional como posibles fuentes de punibilidad de la conducta (artículo 15 del Pacto internacional de los derechos civiles y políticos ${ }^{10}$ ) y en el otro la referencia a la fuente que debe describir la conducta punible es genéricamente al "derecho aplicable" (artículo 9 de la Convención americana sobre derechos humanos ${ }^{11}$ ).

Aun sin enterar una interpretación detallada respecto de los tipos penales contenidos en la Ley $\mathrm{N}^{\circ} 20.357$, es posible realizar la constatación general de que es una ley que ha cumplido en su dictación con todas las formalidades requeridas para ser tal, rige para el futuro ${ }^{12}$ y que describe tanto conductas punibles como las penas asignadas a cada caso, ya sea directamente o por reenvío, cumpliendo así con los presupuestos generales del principio de legalidad de conformidad con nuestro ordenamiento jurídico.

\section{2) LAS LEYES PENALES EN BLANCO CON REENVÍO AL DERECHO INTERNACIONAL}

En varias ocasiones, la Ley $\mathrm{N}^{\circ} 20.357$ se vale de reenvíos a otras disposiciones. En la mayoría de los casos estos reenvíos son a otras disposiciones de la misma ley ${ }^{13}$ o al Código Penal ${ }^{14}$. Los reenvíos al derecho

10 "1. Nadie será condenado por actos u omisiones que en el momento de cometerse no fueran delictivos según el derecho nacional o internacional. Tampoco se impondrá pena más grave que la aplicable en el momento de la comisión del delito. Si con posterioridad a la comisión del delito la ley dispone la imposición de una pena más leve, el delincuente se beneficiará de ello. 2. Nada de lo dispuesto en este artículo se opondrá al juicio ni a la condena de una persona por actos u omisiones que, en el momento de cometerse, fueran delictivos según los principios generales del derecho reconocidos por la comunidad internacional".

11 Principios de legalidad y de retroactividad: "Nadie puede ser condenado por acciones u omisiones que en el momento de cometerse no fueran delictivos según el derecho aplicable. Tampoco se puede imponer pena más grave que la aplicable en el momento de la comisión del delito. Si con posterioridad a la comisión del delito la ley dispone la imposición de una pena más leve, el delincuente se beneficiará de ello".

12 El artículo 44 se preocupa de permanecer neutral respecto del derecho aplicable para hechos acaecidos con anterioridad a su entrada en vigencia: "Los hechos de que trata esta ley, cometidos con anterioridad a su promulgación, continuarán rigiéndose por la normativa vigente a ese momento. En consecuencia, las disposiciones de la presente ley solo serán aplicables a hechos cuyo principio de ejecución sea posterior a su entrada en vigencia”.

13 Así, los artículos del 3 al 10 remiten al artículo 1 (elemento de contexto de los crímenes de lesa humanidad), el artículo $8 \mathrm{~N}^{\circ} 1$ remite al 7 número 1 y 2, el artículo 8 remite al $7 \mathrm{~N}^{\circ} 2$. El artículo 12 remite al 11, el 14 remite a los artículos 3 al 6, igual que el 15, para especificar la pena; el artículo 17 se remite al 17, el 19 al 18, el 20 inciso primero al 5 inciso primero $\mathrm{N}^{\circ} 6,8$ y 9 , el 20 inciso tercero al artículo 5 inciso segundo, el artículo 22 remite al 7 y el 22 al 4 .

14 Esto sucede en los siguientes artículos, relativos a crímenes de lesa humanidad: artículo 5 inciso $1 \mathrm{~N}^{\circ}$ 8: en cuanto a la violación, remite a los artículos 361 y 362 del Código Penal y en cuanto al abuso sexual, remite al artículo 365 bis del Código Penal. En el inciso segundo, 
internacional son menos frecuentes, pero más relevantes para el tema que nos ocupa. Estas remisiones al derecho internacional se encuentran a propósito de los crímenes de guerra. Allí se definen términos que inciden en la determinación de conductas punibles remitiendo a tratados internacionales ${ }^{15}$. Esta técnica legislativa es explicable, tratándose de crímenes de guerra, por la frondosidad de la regulación del derecho internacional humanitario. Son las infracciones punibles al derecho internacional humanitario las que en derecho penal internacional reciben el nombre de crímenes de guerra ${ }^{16}$; y estas remisiones al derecho internacional justamente en esta materia dan cuenta de que es también de esa forma como la ley chilena entiende esa denominación, declarando punibles -también conforme al derecho interno- ciertas infracciones al derecho internacional humanitario.

Al tener incidencia en la determinación precisa de la conducta punible, podría entenderse que estas remisiones dan lugar a leyes penales en blanco, pues para completar con exactitud la información acerca de qué conducta puede ser castigada es necesario acudir a una fuente distinta de la disposición penal que se ocupa de la descripción de la conducta. Con todo, siguiendo la opinión mayoritaria de la doctrina sobre el punto, en los casos de reenvío al derecho internacional previstos en la Ley $\mathrm{N}^{\circ} 20.357$ no se contravendría el principio de legalidad, pues se trata de casos en los que aun prescindiendo de la remisión, resulta reconocible qué es lo prohibido y lo que desea proteger ${ }^{17}$. En particular acerca de la posibilidad de un reenvío al derecho internacional, si bien la mayoría de

remite a los mismos artículos al referirse a las penas aplicables; artículo 7, que se refiere a la tortura como crimen de lesa humanidad, remite a las lesiones del artículo 397 del Código Penal para agravar la pena en caso de que concurran; el artículo 8 se refiere nuevamente al abuso sexual y la violación, remitiendo esta vez a los artículos 366, 366 bis, 366 ter y 363; el artículo 15, sobre asociación ilícita para cometer crímenes de lesa humanidad o genocidio remite, en general, a "las disposiciones del Código Penal".

15 Ocurre así en la definición legal de personas y bienes protegidos, artículo 17 letras d) y e), y en la descripción de crímenes de guerra relacionados con la prohibición de perfidia (artículo 28 de la Ley $\mathrm{N}^{\circ} 20.357$ ).

16 A saber, el mismo Estatuto de Roma remite varias veces a los Convenios de Ginebra de 1949, al igual que lo hace el Código Penal internacional alemán, por citar solo dos ejemplos.

17 Ese es el criterio de legitimidad que sigue la doctrina mayoritaria. Así, KuHLi; Milan (2010) Das Völkerstrafgesetzbuch und das Verbot des Strafbegründung durch Völkergewohnheitsrecht. Berlín, Duncker \& Humblot, p. 257; Politoff/Matus/Ramírez (2003) 97. Cury (2005) 179, señala que las leyes penales en blanco son válidas solo si se describe "inmediatamente la acción u omisión que bajo ciertos presupuestos puede ser castigada por una pena, abandonando a la disposición complementaria solo la precisión de las condiciones en que eso ocurriría”. El mandato constitucional alcanza a la conducta (no necesariamente presupuestos de punibilidad) y esta debe estar descrita de manera expresa, no necesariamente exhaustiva. En la misma línea, Etcheberry Orthusteguy, Alfredo (2005). Derecho Penal, parte general, tomo I. Santiago, Editorial Jurídica de Chile, $3^{\mathrm{a}}$ ed., pp. 84 y ss., quien hace notar que el anteproyecto de texto constitucional incluía la voz "completa" (expresa y completa) refiriéndose a la descripción legal, desechándose en definitiva la exigencia de que esta fuera "completa". 
la doctrina calla, voces de la doctrina nacional y comparada prevén expresamente esa posibilidad, sin considerarla problemática de cara a principio de legalidad ${ }^{18}$.

En la Ley $\mathrm{N}^{\circ} 20.357$, los casos de reenvío se concentran en la descripción de las que son personas protegidas y de los que son bienes protegidos en el derecho internacional humanitario, además de encontrarse en la tipificación de delitos que expresión de la prohibición de perfidia como modo de hacer la guerra ${ }^{19}$. Respecto de las personas protegidas por el derecho internacional, la determinación de esa calidad no obsta a comprender cuál es la conducta que en definitiva es punible, como resulta de la lectura del artículo 18: "[e]l que mate a una persona protegida", o el artículo 25 "se castigará al que ejecutare a una persona protegida sin sentencia previa". Algo análogo ocurre en el caso de la remisión al derecho internacional para determinar cuáles son los bienes protegidos. Así, el artículo 27 expresa: "el que destruyere o se apropiara a gran escala de bienes del enemigo o bienes protegidos". En cuanto a las conductas del artículo 28, que tipifica delitos que son manifestación de la prohibición de perfidia como método de combate, en lo esencial también la conducta está descrita: usar la bandera, insignia o uniforme del enemigo mientras se lleva a cabo un ataque (artículo 28 letra b) de la Ley $\mathrm{N}^{\circ} 20.357$ ) ya resulta bastante descriptivo como conducta; al igual que usar la bandera, insignia o uniforme de Naciones Unidas o los emblemas distintivos de los Convenios de Ginebra (artículo 28, letras c) y d)).

Se cumple en los casos contemplados en la Ley $\mathrm{N}^{\circ} 20.357$, a pesar del reenvío al derecho internacional, la función comunicativa de la tipificación: las personas pueden enterarse de los comportamientos que deben evitar para no quedar sujetos a una pena.

\section{3) LA INTERPRETACIÓN DE LAS LEYES PENALES Y EL PRINCIPIO DE LEGALIDAD}

Existiendo una ley que describe "expresamente" las conductas punibles, el principio de legalidad nada dice de su interpretación. Este principio está vinculado, eso sí, a un límite ampliamente reconocido de

\footnotetext{
18 En doctrina nacional, CuRY (2005) 182: "en general parece no haber inconveniente para que el complemento de una ley en blanco se encuentre [...] en normas de carácter internacional con vigencia supraestatal." En doctrina extranjera (pero también de familia continental) Cerezo Mir, José (2006). Obras completas: Derecho Penal, Parte General. Lima, Ara editores, p. 239, refiriéndose al Código penal español "El Código Penal se remite en ocasiones no solo a los tratados internacionales, sino al derecho de gentes en general, que en gran parte es de carácter consuetudinario. La costumbre internacional adquiere así relevancia como fuente del derecho penal interno."

19 Al respecto, Henckaerts, Jean-Marie y Doswald-Beck, Louise (eds.) (2005). Customary International Humanitarian Law (vol. 2). Cambridge, Cambridge University Press, pp. 1368 y ss.
} 
la interpretación jurídica: el del sentido literal posible. Según la opinión mayoritaria, este es el límite entre la permitida interpretación y la prohibida aplicación analógica del derecho penal, que importaría aplicar la disposición a casos que, quedando fuera de su sentido literal posible, invitan a un razonamiento jurídico similar ${ }^{20}$. Para el derecho penal en los Estados de familia continental, el análisis del sentido literal tiene como objeto el tipo penal determinado por una ley. En este caso estará determinado por el tenor literal de la Ley $\mathrm{N}^{\circ} 20.357^{21}$.

\section{2) LOS CRITERIOS DE INTERPRETACIÓN DE LAS LEYES PENALES USUALMENTE RECONOCIDOS}

Seguiremos aquí la posición mayoritaria en cuanto a que la interpretación de la ley penal no escapa a los criterios clásicos de interpretación: gramatical, teleológico, histórico y sistemático, ${ }^{22}$ recogidos en nuestra legislación en los artículos 19 y siguientes del Código Civil ${ }^{23}$. Pasaremos revista uno a uno, deteniéndonos en aquellos que revisten especial importancia para referirnos a la pertinencia del recurso al derecho internacional en la interpretación de la Ley $\mathrm{N}^{\circ} 20.357$.

\section{1) CRITERIOS VINCULANTES}

De conformidad con el artículo 23 del Código Civil, los criterios que enuncian los artículos 19 al 22 de esa ley son vinculantes. Señala textualmente: [1]a extensión que deba darse a toda ley se determinará por su genuino sentido y según las reglas de interpretación precedentes", disponiendo asimismo que "lo favorable u odioso de una disposición no se tomará en cuenta para ampliar o restringir su aplicación”. Pasemos, en

20 Danckert, Peter (1967). Die Grenze zwischen der extensiven Auslegung und der Analogie in Strafrecht, autoedición, en particular pp. 105 y ss., defiende esta tesis, sin perjuicio de presentar antes opiniones disidentes; Roxin, Claus (2006). Strafrecht Allgemeiner Teil. Munich, C. H. Beck, pp. 148 y ss., número marginal 26 y ss.; Simon, Eric (2005). Gesetzesauslegung im Strafrecht. Berlín, Duncker \& Humblot, pp. 100 y siguientes. En la doctrina chilena, Matus (2012) 177 y ss., 193 y ss.; Novoa (2005) 141 y ss.; Cury (2005) 201; Garrido Montt, Mario (2007). Derecho Penal, tomo I, parte general. Santiago, Editorial Jurídica de Chile, $2^{\text {a }}$ ed. reimpresa, pp. 103 y ss.

21 El tema de dónde está ese tenor literal posible para cada uno de los preceptos de la Ley $\mathrm{N}^{\circ}$ 20.357 quedará pendiente. En cuanto a la interpretación considerando el derecho internacional serán especialmente interesantes los reenvíos al Código Penal, pues allí ya hay una cierta interpretación que se ha venido dando y que no es en todos los casos equivalente a la forma en que en el derecho internacional se comprenden esas conductas. La violación es un buen ejemplo de ello.

22 En profundidad Simon (2005) 676 pp.

23 Matus (2012) 63, 186 y ss., con más referencias; Cury (2005) 190; Garrido (2007) 99 y ss.; Novoa (2005) 134 y ss.; Etcheberry (2005) 99 y ss. 
primer lugar, revista a los criterios vinculantes que tendrán aplicación en todos los supuestos en los que hayan de ser interpretadas leyes penales: el tenor literal (según definición legal, sentido técnico o sentido corriente, según los casos) y el contexto de la ley. Es relevante anotar que el recurso a la finalidad de la ley solo tiene cabida si no se da el supuesto de que "el sentido de la ley es claro" basándose en su tenor literal.

\subsection{1) El tenor literal}

El primer criterio de interpretación implica detenerse en la literalidad de la descripción de la conducta punible. Para ello, de acuerdo a los artículos 19 inciso primero, 20 y 21 del Código Civil chileno, el mandato legal es atender al sentido corriente ${ }^{24}$ de las palabras que se utilicen, salvo que algún término esté definido en la ley ${ }^{25}$ o tenga un sentido técnico del cual no "aparezca claramente" que ha buscado apartarse.

Por su especial importancia para los efectos de la interpretación de la ley de marras, nos detendremos en los términos de la ley que tienen un significado técnico particular. Dice al respecto el artículo 21 del Código Civil: "Las palabras técnicas de toda ciencia o arte se tomarán en el sentido que les den los que profesan la misma ciencia o arte; a menos que aparezca claramente que se han tomado en sentido diverso". Esta disposición se aplica igualmente al lenguaje técnico-jurídico ${ }^{26}$.

Las ya varias décadas de aplicación que ha tenido el derecho penal internacional hacen que haya ido forjando y precisando, mediante su sistema de fuentes y de determinación de reglas de derecho, nociones técnicas acerca de aquello en lo que consisten más precisamente los crímenes de genocidio, de lesa humanidad y el genocidio, las formas de responsabilidad que se reconocen, las circunstancias eximentes de responsabilidad penal, en fin, un cúmulo de expresiones han ganado una significación técnica propia de esa rama del Derecho, han pasado a ser lenguaje técnico, lo

24 La corriente mayoritaria en la doctrina nacional entiende que la expresión "sentido natural y obvio" que utiliza el Código Civil en su artículo 20, ha de entenderse como el sentido corriente de las palabras, que coincide con su utilización usual, y no necesariamente en todos los casos con las acepciones que respecto de cada término particular puedan encontrarse en el Diccionario de la Real Academia de la Lengua española. Garrido (2007) 100; EtchebeRRY (2005) 104; Cury (2005) 193 y s.

25 Esto sucede en algunos casos en la Ley $\mathrm{N}^{\circ}$ 20.357. Así, encontramos definiciones en el artículo 2, en el artículo 17 y en el artículo19. En algunas de esas definiciones remiten a tratados internacionales, como se mencionó supra.

26 En doctrina nacional, Cury (2005) 172. En un sentido análogo, Novoa (2005) 119. En el mismo sentido, sin bien claramente o referido a la ley chilena, sino en general manifestando que en los casos en los que la ley penal toma términos de alguna rama del derecho, los recibe con su sentido técnico, Roxin (2006) 160 y s., número marginal 49; seńalando que la opinión mayoritaria en doctrina es que el sentido técnico jurídico prima por sobre el común, Simon (2005) 82. 
que explica en parte que hoy existan no solo abundantísima literatura al respecto, ${ }^{27}$ sino también cursos y programas de estudios especializados en derecho penal internacional. En la Ley $N^{\circ} 20.357$ se dota a las descripciones de conductas punibles de ciertos nombres, que son términos técnicos en el derecho penal internacional.

De este modo, resulta innegable que expresiones como "genocidio", "crímenes de guerra" y "crímenes de lesa humanidad" tienen un sentido técnico, y no hay ningún indicio de que el legislador chileno haya tomado estas expresiones -en general- en un sentido diverso en la Ley $\mathrm{N}^{\circ}$ 20.357, ni menos aún eso aparece claramente, que es el estándar que fija el artículo 21 del Código Civil. Al contrario, resulta llamativo que muchas veces el texto de la ley es incluso bastante similar al de los tratados, como se nota sobre todo en la tipificación del genocidio ${ }^{28}$, en parte de la descripción del elemento de contexto para los crímenes de lesa humani$\mathrm{dad}^{29}$, y en la tipificación de algunos delitos en particular ${ }^{30}$. Así las cosas, no solo podrá, sino que deberá tomarse en cuenta entonces, a la hora de la interpretación judicial de la ley, el sentido de esas expresiones en el derecho penal internacional, siempre que ellas se usen y no "aparezca claramente" que se les quiere dar un sentido diverso.

\subsection{2) El contexto de la ley}

De conformidad con el inciso primero del artículo 22 del Código Civil, "[e]l contexto de la ley servirá para ilustrar el sentido de cada una de sus partes, de manera que haya entre todas ellas la debida correspondencia y armonía. Esta disposición es importante al interpretar la Ley $\mathrm{N}^{\circ}$ 20.357, sobre todo por la compleja estructura de los tipos penales, respecto de los cuales se describen primero requisitos comunes y luego una serie de requisitos específicos. Será entonces relevante no perder de vista la descripción en su conjunto, y así, tener presente - por ejemplo-cuándo se

27 Para más referencias sobre cada tema mencionado en específico, puede consultarse WERLE (2011) en particular, pp. 282 y ss., 327 y ss., 410 y ss., 462 y ss., 546 y ss.

28 Basta comparar el artículo 11 de la Ley $N^{\circ} 20.357$ con el artículo 2 de la Convención para la prevención y sanción del delito de genocidio, o el artículo 6 del Estatuto de Roma.

29 Compárese el artículo $1 \mathrm{~N}^{\circ} 1$ de la ley al compararlo con el encabezado del artículo 7 del Estatuto de Roma.

30 Solo por mencionar algunos casos evidentes: el artículo $26 \mathrm{~N}^{\circ} 1$ de la ley chilena, sobre nińos soldados, si se lo compara con el artículo 8.2, letras b) xxvi) y e) vii) del Estatuto de Roma, el artículo 28 letras b), c) y d) en comparación con el artículo 8.2 b) viii) del Estatuto de Roma uso prohibido de emblemas, banderas, insignias y uniformes; el artículo $28 \mathrm{f}$ ) y g) de la ley chilena frente al artículo 8.2.b) ix) del Estatuto; el artículo 28 e) de la ley chilena frente al artículo 8.2.b) vi) del Estatuto; el artículo 31.a) de la ley chilena frente al artículo 8.2.b) vii) del Estatuto; el artículo $32 \mathrm{~N}^{\circ} 3$ de la ley chilena frente al artículo 8.2.a) v) del Estatuto; el artículo $32 \mathrm{~N}^{\circ} 5$ de la ley chilena frente al artículo 8.2.b) xxiii) del Estatuto; el artículo 33 de la ley chilena frente al artículo 8.2.b) xiv) del Estatuto de Roma. 
esté ante un homicidio, una violación o un acto de tortura como crimen de lesa humanidad, como crimen de guerra o como delitos ordinarios, según los casos.

El inciso segundo del mismo artículo 22 del Código Civil dispone que "[l] os pasajes obscuros de una ley pueden ser ilustrados por medio de otras leyes, particularmente si versan sobre el mismo asunto". Aquí, dentro de "otras leyes" puede traerse a colación al Ley $\mathrm{N}^{\circ} 20.352^{31}$. Esta ley introdujo el artículo 24 transitorio a la Constitución, que en su inciso segundo reza "Chile reafirma su facultad preferente para ejercer jurisdicción penal en relación con la jurisdicción de la Corte. Esta última será subsidiaria de la primera, en los términos previstos en el Estatuto de Roma que creó la Corte Penal Internacional”. Esta jurisdicción “en relación con” la de la Corte Penal Internacional no puede sino versar sobre los delitos de competencia de la misma Corte, ${ }^{32}$ y si se reafirma su carácter preferente es pretendiendo activar-para el evento de la comisión de crímenes contra el derecho internacional en el territorio nacional- el principio de complementariedad ${ }^{33}$ a favor de la jurisdicción nacional. Además, si se revisa la tramitación de la ley que incorporó esta disposición a la Constitución, podrán encontrarse reiteradas referencias a la tipificación en el derecho interno a los delitos de competencia de la Corte como un requisito previo a la aprobación de esta reforma constitucional ${ }^{34}$. Se encuentran allí

31 De 26 de mayo de 2009.

32 Podrían entenderse incluidos también los delitos contra la administración de justicia de la Corte, sobre los que Chile no ha legislado a pesar de la obligación contraída a partir de la Ratificación del Estatuto de Roma y el artículo 70 párrafo 4 de ese tratado.

33 Sobre el principio de complementariedad, CÁrdenas Aravena, Claudia y Fuentes TorriJo, Ximena (coords.) (2012). La Corte Penal Internacional y su relación con las jurisdicciones nacionales: el principio de complementariedad. Santiago, LegalPublishing Thomson Reuters Chile, 266 pp. Kleffrner, Jann y Kor, Gerben (coords.) (2006). Complementary views on complementarity. La Haya, Asser University Press, 181 pp. STAHn, Carsten y El Zeidy, Mohammed (eds.) (2011). The International Criminal Court and complementarity: from theory to practice. Cambridge, Cambridge University Press, 2 vols., 1.292 pp.

34 En Biblioteca del Congreso Nacional. Documento "Historia de la Ley $\mathrm{N}^{\circ} 20.352$ ". Disponible en http://www.leychile.cl/Consulta/portada_hl?tipo_norma=XX1\&nro_ ley $=20352 \&$ anio $=2013$ [fecha de visita 8 de marzo de 2013], se encuentran varias referencias: p. 162 (Constancia que deja el senador Larraín): "habiéndose legislado en Chile sobre los delitos que conoce la Corte, los crímenes de guerra, de lesa humanidad y de genocidio, y encontrándose tipificados en nuestra legislación tales delitos [...], al ratificarse el Tratado Chile tendrá las herramientas legales para aplicar su jurisdicción penal, siendo de esa manera la de la Corte una jurisdicción complementaria". "De otra manera, agregó, [...] el tribunal podía verse obligado a actuar directamente, lo que habría significado no solamente una capitis diminutio para nuestra soberanía jurisdiccional, lo que sería inaceptable, sino que además se habría perdido el sentido la Corte, que es actuar en forma complementaria, en situaciones muy específicas que contiene el Estatuto que creó a la propia Corte". En el mismo sentido se encuentran declaraciones de otros parlamentarios en las páginas 176 (Espina), 184 (Romero), 185 (Cantero), 190 (Larraín), 205 (Coloma), 230 (Moreira, quien especifica que "se tipificaron en la legislación nacional los delitos que sanciona la corte", 244 (Araya). En pp. 245 y s., Edgardo Riveros, subsecretario general de la Presidencia, señaló: "la respon- 
reiteradamente expresiones como "se tipificaron en la legislación nacional los delitos que sanciona la corte". Teniendo en cuenta que la Corte Penal Internacional tiene, conforme a su Estatuto, competencia sobre crímenes contra el derecho internacional de genocidio, crímenes de lesa humanidad y crímenes de guerra, si Chile considera que tiene una facultad preferente para ejercer jurisdicción sobre esos crímenes, la que asegura mediante una ley que los tipifica, resulta innegable que conforme a razonamientos sistemáticos que incluyan a todo el sistema jurídico es dable considerar los crímenes bajo la jurisdicción de la Corte a la hora de interpretar la Ley $\mathrm{N}^{\circ} 20.357$, que se relaciona con este inciso segundo de la disposición 24 transitoria de nuestra Constitución Política.

\section{2) CRITERIO SUPLETORIO: LA FINALIDAD DE LA LEY}

Según dispone al artículo 19 inciso segundo del Código Civil, "se puede, para interpretar una expresión obscura de la ley" (obscura habiendo ya examinado su tenor literal, pues si el sentido de la ley resulta claramente de él, no se desatenderá a pretexto de consultar su espíritu), "recurrir a su intención o espíritu, claramente manifestados en ella misma o en la historia fidedigna de su establecimiento". Esta redacción se hace cargo de dos de los criterios clásicos, el teleológico y el histórico, poniendo al segundo al servicio del primero. Las dos alternativas de averiguación de la finalidad de la ley que se ponen a disposición del intérprete (primera: manifestada en ella misma; segunda: manifestada en la historia fidedigna de su establecimiento), podrían entenderse hasta cierto punto como una traducción de la dicotomía entre finalidad objetiva (manifestada en la ley) y finalidad subjetiva, en ocasiones denominada "voluntad del legislador"; pero respecto de este punto cabe destacar que la historia fidedigna del establecimiento de la ley no solamente implica averiguar las motivaciones declaradas por quienes intervinieron en su establecimiento (lo que hoy en parte importante puede conseguirse con relativa facilidad consultando la página web del Congreso Nacional), sino que es menester considerar además los hechos objetivos que precedieron y rodearon al "establecimiento" de la ley (lo que parte de la doctrina llama la occasio $\operatorname{legis}^{35}$ ), y que pueden

sabilidad prioritaria, esencial, para juzgar delitos graves que tienen la condición de delitos internacionales recae en los Estados, es un derecho de ellos y, a la vez, una obligación: el derecho de tener la jurisdicción preferente y la obligación de tener un derecho sustantivo y procesal adecuado para juzgar. Es el paso que tuvimos que dar antes de empezar a discutir esta reforma constitucional; es decir, tipificar los delitos de lesa humanidad y los crímenes de guerra y genocidio. Ya dimos ese paso relacionado con el derecho sustantivo y, desde luego, corresponderá a nuestros tribunales de justicia conocer tales delitos".

ETCHEBERRY (2005) 105. 
colaborar para desentrañar su espíritu, y la política criminal que se siguió al legislar ${ }^{36}$.

También estos criterios nos llevan al derecho internacional, como se explica a continuación.

\subsection{1) Finalidad de la ley manifestada en sí misma}

Como se ha señalado precedentemente, el hecho de que la ley nacional que tipifica los crímenes de guerra, de lesa humanidad y el genocidio utilice terminología y formulaciones propias del derecho internacional, hace que resulte, de su sola lectura, la idea que que su finalidad es incorporar en el derecho interno estos delitos, que atentan contra los bienes jurídicos fundamentales del derecho internacional (la paz, la seguridad y el bienestar de la humanidad). Además, si no se entendiera que hay un desvalor distinto en matar a otra persona en el marco de un ataque contra la población civil, conociendo de dicho ataque, que sin esa circunstancia - por dar un ejemplo- la dictación de esta ley en la forma que finalmente asumió no tendría sentido, pues ella solo se explica si se entiende que las conductas, descritas del modo en que lo hace, dan cuenta de un injusto distinto del mero homicidio simple o calificado, para seguir con el mismo ejemplo ${ }^{37}$. Si en la mayoría de los supuestos se tipifica conductas punibles conforme al derecho internacional y en todos se da al delito el mismo nombre que en el derecho internacional, es porque se busca proteger los mismos bienes jurídicos que en el derecho internacional. Apoya esta conclusión también el hecho de que si para legislar hubiesen primado solamente criterios utilitaristas frente a la jurisdicción de la Corte Penal Internacional, no hubiese sido necesario un articulado tan detallado, pues se legisló abarcando incluso en supuestos en los que no existían lagunas de punibilidad que hubieran facultado a la Corte Penal Internacional para actuar: se requiere allí -someramente- que el asunto (case, que se ha interpretado como hechos punibles imputados a una o más personas) ${ }^{38}$ no esté siendo ni haya sido realmente investigado, perseguido o juzgado (artículos

36 Al respecto, en doctrina nacional, Matus (2012) 63, 182 y ss., 210 y ss.; Garrido (2007) 94 y ss.

37 De hecho, el abarcar el injusto específico de los crímenes contra el derecho internacional fue una de las finalidades reconocidas por el grupo de expertos que estuvo encargado de la redacción de una ley homóloga a la chilena, el Código Penal Internacional alemán. BunDesministerium Der Justiz (ed.) (2001).“'Arbeitsentwurf eines Gesetzes zur Einführung des Völkerstrafregesetzbuchs - mit Begründung- Erstellt von der vom Bundesministerium der Justiz eingesetzten Arbeitsgruppe Völkerstrafgesetzbuch”. Baden-Baden, Nomos, p. 21; Kuhli (2010) p. 36; Kress, Claus (2000). Vom Nutzen eines deutschen Strafgesetzbuchs. Baden-Baden, Nomos, pp. 14 y ss.

38 Rastan, Rod (2011). "Situation and Case: Defining the Parameters". En Stahn, Carsten y El Zeidi, Mohamed (eds.). The International Criminal Court and complementarity: from theory to practice, vol I. Cambridge, Cambridge University Press, pp. 421-459. 
17-20 del Estatuto de Roma) ${ }^{39}$. Para los efectos de esta explicación, el mismo ejemplo del homicidio es elocuente. A mayor abundamiento, con su ratificación del Estatuto de Roma, Chile se ha vinculado también la declaración de ese tratado en cuanto a que los crímenes de guerra, de lesa humanidad y el genocidio "constituyen una amenaza para la paz, la seguridad y el bienestar de la humanidad” (preámbulo, párrafo 3).

\subsection{2) Finalidad de la ley manifestada en la historia fidedigna de su establecimiento}

Hay abundante constancia de que la ley fue dictada a propósito de la aprobación del Estatuto de la Corte Penal Internacional por el Congreso Nacional, que es un trámite previo a su ratificación de conformidad con el artículo $54 \mathrm{~N}^{\circ} 1$ de la Constitución, y para el cual fue necesario un quórum calificado de dos tercios, producto de haberse acogido la acción de inconstitucionalidad presentado por treinta y cinco diputados respecto del Estatuto de Roma de la Corte Penal Internacional. ${ }^{40}$

En definitiva, un sector no estaba dispuesto a aprobar el tratado sin que previamente se hubiera dictado una ley que tipifique en el derecho interno las conductas para las cuales es competente la Corte Penal Internacional, pretendiendo de ese modo que ella no llegue a ejercer su competencia complementaria sobre hecho acaecidos en Chile, la que solo podría llegar a ejercer si Chile no investiga ni persigue realmente esos crímenes. Se confirma así que la Ley $\mathrm{N}^{\circ} 20.357$ se dictó buscando una forma de dar competencia a los jueces chilenos, mediante una ley chilena, para las mismas conductas sobre las que tiene competencia la Corte Penal Internacional, a fin de minimizar las posibilidades de que alguna vez ella llegue a conocer de hechos acaecidos en Chile. Es esto lo que explica que se hayan contemplado las mismas categorías de crímenes que en el tratado. Un extracto de la moción basta a título ilustrativo: "La presente moción tiene por objeto perfeccionar y adecuar la legislación chilena tipificando conductas constitutivas de delitos y crímenes contenidos en el Estatuto de Roma de la Corte Penal Internacional, con miras a la ratificación de dicho tratado" ${ }^{1}$. Los parlamentarios y otras personas que intervinieron en la

39 Mayores antecedentes sobre cómo opera el examen de admisibilidad en Cárdenas AraveNA, Claudia (2005). Die Zulässigkeitsprüfung vor dem Internationalen Stragerichtshof. Berlín, Berliner Wissenschaftsverlag, 248 pp.; sobre esta cuestión en particular, pp. 78 y ss.

40 Tribunal Constitucional. 8 de abril de 2002. Rol No 346-02. "Requerimiento de inconstitucionalidad presentado por treinta y cinco señores Diputados respecto del Estatuto de Roma de la Corte Penal Internacional, adoptado en dicha ciudad el 17 de julio de 1998". Disponible en http://www.tribunalconstitucional.cl/wp/ver.php?id=274 [fecha de visita 8 de marzo de 2013].

41 Biblioteca del Congreso Nacional. Documento "Historia de la Ley No 20.357". Disponible en http://www.leychile.cl/Consulta/portada hl?tipo norma=XX1\&nro $\underline{\text { ley }=20357 \text { \&anio }=2013}$ [fecha de visita 8 de marzo de 2013], p. 4 . 
tramitación de la ley se refirieron también expresamente a tipificar las conductas cuya punibilidad se prevé en el Estatuto de Roma, o a implementar los crímenes de competencia de la Corte Penal Internacional ${ }^{42}$.

La finalidad de la Ley $\mathrm{N}^{\circ} 20.357$ aparece entonces clara y coherente, ya sea que se la averigüe investigando lo que la ley manifiesta "en sí misma" o en la "historia fidedigna de su establecimiento". Se busca tipificar en Chile los delitos sobre los cuales tiene competencia la Corte Penal Internacional, vale decir, los crímenes contra el derecho internacional de genocidio, crímenes de lesa humanidad y crímenes de guerra. Este hallazgo hace que el derecho penal internacional sea relevante en los casos en los que el tenor literal de una disposición concreta contenida en esta ley no entregue una respuesta unívoca.

\section{3) CRITERIOS A APLICAR EN CASO DE INVIABILIDAD DE LOS ANTERIORES}

El artículo 24 del Código Civil dispone que “[e]n los casos en que no pudieren aplicarse las reglas de interpretación precedentes, se interpretarán los pasajes obscuros o contradictorios del modo que más conforme parezca al espíritu general de la legislación y a la equidad natural".

El espíritu general de la legislación es identificable con ciertos principios que informan el ordenamiento jurídico ${ }^{43}$. Nada obsta a que se considere también a los principios "derivados de las Convenciones y Tratados internacionales que han servido para el establecimiento de ciertas regulaciones específicas o su modificación" ${ }^{44}$. Su aplicación conforma un criterio supletorio no en cuanto a que solo haya de echarse mano de ellos en caso de que no sea posible aplicar los criterios que hemos denominado vinculantes, sino en cuanto en ese caso adquieren todavía mayor relevancia, pues son los llamados a flanquear a la equidad natural para resolver

42 Biblioteca del Congreso Nacional. Documento "Historia de la Ley N ${ }^{\circ} 20.357$ ". Disponible en http://www.leychile.cl/Consulta/portada_hl?tipo_norma=XX1\&nro_ ley $=20357 \&$ anio $=2013$ [fecha de visita 8 de marzo de 2013], pp. 29 (Riveros), 54 (Hoffmann), 55 y s. (Viera-Gallo), 58 (Cantero, quien se refiere a "la implementación de manera adecuada del Estatuto de Roma”), 63 (Sabag: "busca no solo perfeccionar nuestra legislación penal interna, sino también adecuarla a las disposiciones de la Corte Penal Internacional”, 66 (Larraín), 84 (Comisión de Derechos Humanos de la Cámara de Diputados), 130 (Ascencio), 138 (Ojeda), 143 (Riveros), 146 (Vidal) "Este proyecto apunta a la penalización, adecuando las normas internas y en correlación con las normas internacionales), 154 (Allende: "vamos a adecuar la legislación penal interna, tipificando las conductas sancionadas en el Estatuto de Roma de la Corte Penal Internacional”). Además en pp. 23 y ss. se listan los tratados que se tuvieron a la vista, entre los que destaca por cierto el Estatuto de Roma.

43 En materia penal, pueden nombrarse la prohibición de doble valoración, el principio de legalidad y el principio pro reo, a título ejemplar.

44 Matus (2012) 216. Como ha puesto de relieve el mismo autor, en los últimos años se ha vuelto usual que las modificaciones del derecho penal material se justifiquen en el cumplimiento de obligaciones internacionales. 
los dilemas interpretativos. Tratándose de criterios de interpretación, su aplicación no puede implicar la creación de nuevos delitos ${ }^{45}$, tanto porque eso implicaría pasar de una interpretación a una aplicación analógica como porque justamente colisionaría contra uno de los principios reconocidos en materia penal, como es el principio pro-reo ${ }^{46}$.

\section{3) EL EJEMPLO ALEMÁN: LA PREFERENCIA DE LA INTERPRETACIÓN FAVORABLE AL DERECHO INTERNACIONAL "VÖLKERRECHTSFREUNDLICHE AUSLEGUNG"}

El verse enfrentados a una ley estatal que tipifique delitos que tienen su fuente de punibilidad (también) en el derecho internacional, dista de ser un fenómeno solamente chileno.

Desde hace unos 15 años, muchos países han venido dictando lo que se conoce como "leyes de implementación" (implementing legislation) del Estatuto de Roma ${ }^{47}$, que suelen incluir varias materias, entre las que se cuentan la tipificación en el derecho de los crímenes contra el derecho internacional $^{48}$, ya sea que esto último se haga en el Código Penal o en una ley especial ${ }^{49}$. Esta tendencia parece obedecer, en casos como el chileno, más a la conveniencia político-jurídica de la implementación ${ }^{50}$, que solamente a un afán de cumplir con obligaciones de incriminación, que el Estatuto de Roma no establece, y en cambio sí surgen de tratados ratificados con bastante antelación ${ }^{51}$. 
Este modo de proceder se justifica, sobre todo, en Estados de familia del derecho continental, que entienden que el principio de legalidad implica la necesidad de contar con una lex scripta, incompatible con sistema de fuentes del derecho internacional. Estos Estados, entonces, si quieren juzgar por sus propios tribunales las conductas punibles conforme al derecho internacional: genocidio, crímenes de lesa humanidad, crímenes de guerra y crímenes contra la paz, deben legislar al respecto, tipificando en su derecho interno esas conductas y especificando las penas que les asignan.

El caso alemán es relevante para examinar el chileno, principalmente, porque se trata de un país de tradición continental, como el nuestro, con una dogmática penal y una noción del principio de legalidad del que nuestro sistema es tributario. Es más, el sistema alemán tiene una disposición constitucional que es un obstáculo para la determinación de conductas punibles directamente a partir del derecho internacional consuetudinario: el artículo 103 inciso 2 de la Ley Fundamental alemana prohíbe fundar la responsabilidad en la costumbre. Fue esto, unido a la falta de determinación de la pena en los tratados internacionales o en los principios de derecho internacional lo que hizo necesario, en opinión mayoritaria ${ }^{52}$, un Código Penal Internacional alemán para la investigación y persecución nacional de los crímenes de guerra, de lesa humanidad y de genocidio ${ }^{53}$. De este modo, es la descripción legal la que funda la punibilidad de la conducta para el derecho interno. Aunque existan reenvíos al derecho internacional (que los hay en la ley), siendo reconocible qué es lo prohibido y lo que desea proteger, conforme a las reglas generales para la legitimidad de leyes penales en blanco, no habría problemas de constitucionalidad ${ }^{54}$.

Además, en la implementación de crímenes de guerra, crímenes de lesa humanidad y genocidio se optó, igual que luego en Chile, por una ley especial, el así llamado "Código Penal Internacional" (Völkerstrafgesetzbuch, $V S t G B)^{55}$, prefiriéndose esa opción de implementación para facilitar el estudio de la materia y también para servir de ejemplo para otros Estados, apostando por una influencia en legislaciones extranjeras ${ }^{56}$. La

Safferling, Christoph (2011). Internationales Strafrecht. Berlín, Springer, p. 319; Satzger, Helmut (2012). International and European Criminal Law. Munich, C. H. Beck, pp. 281 y ss., número marginal 10 y ss. En contra, no era necesario, pues con pequeños ajustes hubiera bastado para salvar eventuales lagunas de punibilidad, y con ello esta ley conlleva todos los riesgos del derecho penal simbólico, DefFert (2011) 187 y ss., 222 y s.

Aunque este último se encontraba tipificado ya en el artículo 220 a) del Código Penal alemán. Para un breve estudio acerca de esa ley en español, Werle, Gerhard y Jessberger, Florian (2003). "La punibilidad de los crímenes internacionales en el derecho interno alemán, El Código penal internacional alemán”. Revista penal 12, pp. 126-142.

54 Kuhli (2010) 284 pp., especialmente pp. 113 y ss., 246 y s., 257. Más escéptico se muestra SATZger (2012) 290 y ss., número marginal 23 y ss.

55 Disponible en http://www.gesetze-im-internet.de/bundesrecht/vstgb/gesamt.pdf [fecha de visita 8 de marzo de 2013].

56 Bundesministerium Der Justiz (2001) 21. 
ley alemana es producto del trabajo de una comisión de seis expertos ${ }^{57} \mathrm{y}$ entró a regir prácticamente junto con el Estatuto de Roma, el año 2002. A la fecha de escribir este texto, hay un caso en curso en el que la aplica el Código Penal internacional alemán, habiéndose desechado su uso en varios otros ${ }^{58}$ por la autoridad federal que tiene a su cargo, de manera exclusiva, la investigación y persecución de esta clase de delitos, el Fiscal Federal General (Generalbundesanwalt).

En cuanto a la interpretación del Código Penal Internacional alemán, se ha entendido que debe procederse considerando tanto el Estatuto de Roma de la Corte Penal Internacional como el derecho internacional consuetudinario ${ }^{59}$. Esta conclusión se funda, tanto de los criterios tradicionales de interpretación de la ley (gramatical, sistemático, histórico, teleológico), para los cuales podemos referirnos - mutatis mutandis- a las explicaciones anteriores (también allí se utilizaron los nomen iuris del derecho penal internacional y hay constancia de que la ley es parte del compromiso del Estado para con la persecución nacional de estos crímenes); como en el artículo 25 de la Ley Fundamental alemana ${ }^{60}$, conforme a la cual las reglas generales del derecho internacional son parte integrante del derecho federal, teniendo un valor superior a la ley y creando directamente derechos y deberes para los habitantes del territorio federal. Dentro de la expresión "reglas generales del derecho internacional" se comprenden normas de ius cogens, de derecho consuetudinario y a los principios de derecho reconocidos por las naciones (artículo 38 inciso primero letra c) del Estatuto de la Corte Internacional de Justicia) ${ }^{61}$.

Cabe resaltar que el artículo 25 de la Ley Fundamental alemana -que no tiene un equivalente de la misma amplitud en el derecho constitu-

58 El caso que se sigue tiene como imputados contra dos ruandeses a los que se imputa crímenes cometidos como líderes de las FDLR (Forces Démocratiques de Libération du Rwanda”. Entre los procesos que en definitiva no han seguido adelante, acaso el más connotado fue el que se siguió contra Georg Klein, como responsable de un ataque aéreo en Kunduz, Afganistán. También se ha intentado seguir procesos contra Donald Rumsfeld, por lo sucedido en Abu Ghraib y Guantánamo Bay, y contra el primer ministro de Usbequistán, Almatow. Se puede consultar información más detallada en http://www.generalbundesanwalt.de/de/ aktuell.php?searchstring=V\%F6lkerstrafgesetzbuch, consultado el 8 de marzo de 2013.

59 Werle, Gerhard (2012). Völkerstrafrecht, Tübingen, Mohr Siebeck, pp. 176 y s., número marginal 381 y ss. Se hace de este modo en el "Münchner Kommentar zum Strafgesetzbuch", Band 6/2 (Nebenstrafrecht III, Völkerstrafgesetzbuch), además de que ya el nombre oficial de la ley es bastante indicativo. De hecho, resulta llamativo que esta ley se comente tanto en los comentarios de derecho penal interno (como el recién citado Münchner Kommentar), como en los libros dedicados al derecho penal internacional, SATZGER (2012) 277 y ss.; Werle (2011) 223 y ss., Safferling (2011) 319 y ss.

60 http://www.gesetze-im-internet.de/bundesrecht/gg/gesamt.pdf, consultada el 8 de marzo de 2013.

61 Talmon, Stefan (2013). Die Grenzen der Anwendung des Völkerrechts im deutschen Recht. Juristenzeitung 1/2013, pp. 12-21, en particular p. 12, con más referencias. 
cional chileno- solo sirve para confirmar la conclusión a la que se llega también por la aplicación de los criterios tradicionales de interpretación, no la funda exclusivamente ${ }^{62}$. Es más, por la limitante que importa el artículo 103 de la Ley Fundamental alemana, para llegar a aplicar su artículo 25 en la interpretación del Código Penal Internacional alemán, resulta fundamental haber arribado antes, mediante la interpretación por los criterios tradicionales, a la conclusión de que esa ley penal estatal (el Código penal internacional alemán) implementa los crímenes contra el derecho internacional en el derecho interno, entender por ejemplo que emplea -en algunos casos- términos técnicos del derecho internacional. De lo contrario, no sería pertinente invocar el artículo 25 de la Ley Fundamental, pues el artículo 25 solo es aplicable a las reglas de derecho internacional, y la prohibición del artículo 103 obstaría a ello en lo que toca a materias penales. Esta misma constatación sirve para confirmar la idea expresada anteriormente respecto del derecho nacional: tanto del texto de la ley como de su consenso y finalidades resulta que varias de las expresiones de la ley interna que tipifica crímenes de guerra, de lesa humanidad y genocidio son términos técnicos, y como tales han de interpretarse, siguiendo el significado que les da el derecho (penal) internacional, a menos que aparezca claramente que se les ha dado otro uso, lo que ocurrirá básicamente cuando una interpretación conforme al derecho internacional no sea compatible con el tenor literal de la disposición legal.

\section{CONCLUSIONES}

La Ley $\mathrm{N}^{\circ} 20.357$ describe conductas punibles utilizando palabras, como toda ley. Esas palabras tienen un significado especificado en el derecho penal internacional. ¿Puede utilizarse este, entonces, para interpretar las palabras de la ley interna? El principio de legalidad no se opone a ello. Si las palabras de la ley penal pueden interpretarse siguiendo valoraciones sociales o doctrinales ${ }^{63}$, pueden interpretarse también conforme al derecho internacional. Este puede aportarle no solo un sentido literal posible, sino acaso muchas veces el más plausible para el caso particular de la ley en comento. Ni contraría ello a la Constitución, mientras se respeten los límites a toda interpretación jurídica, y en particular la prohibición de analogía en materia penal, ni menos se opone a la consagración de la garantía de legalidad en los tratados de derechos humanos vinculantes en Chile.

62 Dargue, Tobias (2010). Kriegsverbrechen im nationalen und internationalen Recht, Berlín, Springer, pp. 298 y s., a propósito de los crímenes de guerra.

63 Reconocidas expresamente como posible fundamento de un fallo en materia penal en el artículo 342 letra d) del Código Procesal Penal. 
El reenvío al derecho internacional tampoco implica un incumplimiento del principio de legalidad mientras se cumpla con que resulte reconocible qué es lo prohibido y lo que desea proteger, lo que se cumple para los casos detectados en la Ley $\mathrm{N}^{\circ} 20.357$.

En lo que toca al examen de los criterios de interpretación, hemos podido constatar resultados consistentes: los criterios de interpretación que manda utilizar la legislación nacional nos llevan al derecho (penal) internacional para la correcta interpretación de la Ley $\mathrm{N}^{\circ} 20.357$ : el significado técnico de muchos de los términos utilizados, el contexto de la ley, la intención que se deduce tanto de ella misma como de la historia de su establecimiento llevan a entender que ella ha de interpretarse conforme al derecho (penal) internacional, respetando por cierto el límite del significado posible atendiendo al tenor literal. De allí que sea posible predicar, también para Chile, la máxima de interpretación aceptada para el Código Penal Internacional alemán: también para la Ley $N^{\circ} 20.357$ ha de preferirse, en general, entre las interpretaciones posibles, la que coincida de mejor manera con el derecho (penal) internacional.

\section{BIBLIOGRAFÍA}

\section{LITERATURA}

- Bassiouni, M. Cherif (2001). "Universal jurisdiction for international crimes: Historical perspectives and contemporary practice", Virginia Journal of International Law 42.

- Benavides, Luis (2001). "The Universal Jurisdiction Principle: nature and scope". 1 Anuario Mexicano de Derecho Internacional.

- Cárdenas Aravena, Claudia (2005). Die Zulässigkeitsprüfung vor dem Internationalen Strafgerichtshof. Berlín, Berliner Wissenschaftsverlag, $248 \mathrm{pp}$.

- Cárdenas Aravena, Claudia (2006). "Los crímenes del Estatuto de la Corte Penal Internacional en el derecho chileno, necesidad de una implementación”. Política Criminal no 2, A1, 2006, pp. 1-17. Disponible en: http://www.politicacriminal.cl/n_02/a_1_2.pdf [fecha de visita 8 de marzo de 2013].

- Cárdenas Aravena, Claudia y Fuentes Torrijo, Ximena (coords.) (2012). La Corte Penal Internacional y su relación con las jurisdicciones nacionales: el principio de complementariedad. Santiago, LegalPublishing Thomson Reuters Chile.

- Cerezo Mir, José (2006). Obras completas: Derecho Penal, Parte General. Lima, Ara Editores.

- Cury Urzúa, Enrique (2005). Derecho Penal, parte general. Santiago, Ediciones Universidad Católica de Chile. 
- Dargue, Tobias (2010). Kriegsverbrechen im nationalen und internationalen Recht, Berlín, Springer.

- Danckert, Peter (1967). Die Grenze zwischen der extensiven Auslegung und der Analogie in Strafrecht. autoedición.

- DefFert, Dietmar (2011). Strafgesetzlichkeit als völkerstrafrechtliches Legitimationsprinzip, Frankfurt am Main, Peter Lang.

- Etcheberry Orthusteguy, Alfredo (2005). Derecho Penal, parte general, tomo I. Santiago, Editorial Jurídica de Chile, $3^{\mathrm{a}} \mathrm{ed}$.

- Garrido Montt, Mario (2007). Derecho Penal, tomo I, parte general. Santiago, Editorial Jurídica de Chile, $2^{a}$ ed. reimpresa.

- Henckaerts, Jean-Marie y Doswald-Beck, Louise (eds.) (2005). Customary International Humanitarian Law (vol. 2). Cambridge, Cambridge University Press.

- Inazumi, Mitsue (2005). Universal Jurisdiction in Modern International Law: Expansion of National Jurisdiction for Prosecuting Serious Crimes under International Law. Antwerpen, Intersentia.

- Kleffrner, Jann y Kor, Gerben (coords.) (2006). Complementary views on complementarity. La Haya, Asser University Press.

- Kress, Claus (2000). Vom Nutzen eines deutschen Strafgesetzbuchs. Baden-Baden, Nomos.

- Kunli, Milan (2010). Das Völkerstrafgesetzbuch und das Verbot des Strafbegründung durch Völkergewohnheitsrecht. Berlín, Duncker \& Humblot.

- Landogny, Otto (redactor del tomo). "Münchner Kommentar zum Strafgesetzbuch", Band 6/2 (Nebenstrafrecht III, Völkerstrafgesetzbuch).

- LeE, Roy (2005). State's responses to issues arising from the ICC Statute. Ardsley, Transnational Publishers.

- Macedo, Stephen (2006). Universal jurisdiction. Pennsylvania, University of Pennsylvania Press.

- Matus Acuña, Jean Pierre (2012). La ley penal y su interpretación. 2a ed., Santiago: Editorial Metropolitana.

- Novoa Monreal, Eduardo (2005). Curso de derecho penal chileno. Parte general, tomo I. Santiago, Editorial Jurídica de Chile, $3^{\mathrm{a}}$ ed.

- Politoff Lifschitz, Sergio, Matus Acuña, Jean Pierre y Ramírez Guzmán, María Cecilia (2003). Lecciones de derecho penal chileno, parte general, Santiago, Editorial Jurídica de Chile, $2^{a}$ ed. actualizada.

- Rastan, Rod (2011). "Situation and Case: Defining the Parameters". En Stahn, Carsten y El Zeidi, Mohamed (eds.). The International Criminal Court and complementarity: from theory to practice, vol I. Cambridge, Cambridge University Press, pp. 421-459.

- Roxin, Claus (2006). Strafrecht Allgemeiner Teil. Munich, C. H. Beck. 
- Safferling, Christoph (2011). Internationales Strafrecht. Berlín, Springer.

- SATZger, Helmut (2012). International and European Criminal Law. Munich, C. H. Beck.

- Simon, Eric (2005). Gesetzesauslegung im Strafrecht. Berlín, Duncker \& Humblot.

- Stahn, Carsten y El Zeidy, Mohammed (eds.) (2011). The International Criminal Court and complementarity: from theory to practice. Cambridge, Cambridge University Press, 2 vols.

- Talmon, Stefan (2013). "Die Grenzen der Anwendung des Völkerrechts im deutschen Recht". Juristenzeitung 1/2013, pp. 12-21.

- Werle, Gerhard y Jessberger, Florian (2003). "La punibilidad de los crímenes internacionales en el derecho interno alemán, El Código penal internacional alemán”. Revista penal 12, pp. 126-142.

- Werle, Gerhard (2011). Tratado de derecho Penal Internacional. 2a ed. Valencia, Tirant lo Blanch.

- Werle, Gerhard (2012). Völkerstrafrecht, 4ta. ed., Tübingen, Mohr Siebeck.

\section{FUENTES}

- Bundesministerium Der Justiz (ed.) (2001). "Arbeitsentwurf eines Gesetzes zur Einführung des Völkerstrafregesetzbuchs -mit Begründung- Erstellt von der vom Bundesministerium der Justiz eingesetzten Arbeitsgruppe Völkerstrafgesetzbuch”. Baden-Baden, Nomos, 88 pp.

- Biblioteca del Congreso Nacional. Documento "Historia de la Ley $N^{\circ}$ 20.357". Disponible en http://www.leychile.cl/Consulta/ portada_hl?tipo_norma=XX1\&nro_ley=20357\&anio=2013 [fecha de visita 8 de marzo de 2013].

- Biblioteca del Congreso Nacional. Documento "Historia de la Ley $N^{\circ}$ 20.352". Disponible en http://www.leychile.cl/Consulta/ portada_hl?tipo_norma=XX1\&nro_ley=20352\&anio=2013 [fecha de visita 8 de marzo de 2013].

- Código Civil. Disponible en http://www.leychile.cl/Navegar?idNorm $\mathrm{a}=172986$ \&idParte $=8717776$ [fecha de visita 8 de marzo de 2013].

- Código Penal. Disponible en http://www.leychile.cl/ Navegar?idNorma $=1984 \&$ \&idParte $=0$ [fecha de visita 8 de marzo de 2013].

- Código Penal Internacional Alemán (Völkerstrafgesetzbuch, VStGB). Disponible en http://www.gesetze-im-internet.de/bundesrecht/vstgb/ gesamt.pdf [fecha de visita 8 de marzo de 2013].

- Constitución Política de la República de Chile. Disponible en http:// www.leychile.cl/Navegar?idNorma=242302 [fecha de visita 8 de marzo de 2013]. 
- Convención Interamericana sobre Derechos Humanos (Pacto de San José de Costa Rica). Disponible en http://www.oas.org/dil/esp/ tratados_B-32_Convencion_Americana_sobre_Derechos_Humanos. htm [fecha de visita 8 de marzo de 2013].

- Convención para la Prevención y Sanción del Delito de Genocidio de 1948. Disponible en http://www2.ohchr.org/spanish/law/ genocidio.htm [fecha de visita 8 de marzo de 2013].

- Convenios de Ginebra de 12 de agosto de 1949: I. Convenio, para aliviar la suerte que corren los heridos y los enfermos de las Fuerzas Armadas en campaña; II. Convenio, para aliviar la suerte que corren los heridos, los enfermos y los náufragos de las Fuerzas Armadas en el mar; III. Convenio, relativo al trato debido a los prisioneros de guerra; IV. Convenio, relativo a la protección debida a las personas civiles en tiempo de guerra. Disponibles en http://www.icrc.org/spa [fecha de visita 8 de marzo de 2013].

- Corte Penal Internacional, base de datos Legal Tools. Disponible en http://www.legal-tools.org/en/go-to-database/ ltfolder/0_3857/\#results [fecha de visita 8 de marzo de 2013].

- Corte Suprema. 9 de septiembre de 1998. Rol 469-98. "Desaparición de Pedro Poblete Córdova”. Fallos del Mes, N 478, pp. 1760-1769.

- Corte Suprema. 13 de diciembre de 2006. Rol No 559-2004. "Homicidios de Hugo Vásquez Martínez y Mario Superby Jeldres" (caso Molco). Estudios Constitucionales, año $5 \mathrm{~N}^{\circ} 1$, pp. 533-549.

- Corte Suprema. 25 de septiembre de 2008. Rol No 4.662-07. "Episodio Liquiñe" (2008). Disponible en http://www.memoriaviva. com/fallos.htm [fecha de visita 8 de marzo de 2013].

- Corte Suprema. 4 de agosto de 2010. Rol N 7089-09. Homicidio calificado de Rafael Vergara Toledo y el homicidio simple de Eduardo Vergara Toledo". Disponible en http://www.ddhh.gov.cl/ fallosagosto2010.html [fecha de visita 8 de marzo de 2013].

- Estatuto de la Corte Internacional de Justicia. Disponible en http://www. un.org/spanish/aboutun/icjstat.htm [fecha de visita 8 de marzo de 2013].

- Generalbundesanwalt, página web http://www. generalbundesanwalt.de/de/aktuell.php?searchstring=V\%F6lkerstrafg esetzbuch [fecha de visita 8 de marzo de 2013].

- Ley Fundamental alemana (Grundgesetz, GG). Disponible en http:// www.gesetze-im-internet.de/bundesrecht/gg/gesamt.pdf [fecha de visita 8 de marzo de 2013].

- Ley $\mathrm{N}^{\circ}$ 20.357. Disponible en http://www.leychile.cl/ Navegar?idLey=20357 [fecha de visita 8 de marzo de 2013].

- Ley Orgánica Constitucional del Ministerio Público No 19.640. Disponible en http://www.leychile.cl/Navegar?idNorma=145437 [fecha de visita 8 de marzo de 2013]. 
- Pacto Internacional de Derechos Civiles y Políticos. Disponible en http://www2.ohchr.org/spanish/law/ccpr.htm [fecha de visita 8 de marzo de 2013].

- Tribunal Constitucional. 30 de marzo de 2007. Rol 54906, "Requerimiento de inaplicabilidad por inconstitucionalidad presentado por el Juez Presidente de la Segunda Sala del Tribunal Oral en lo Penal de Concepción, respecto del artículo 434 del Código Penal, en la causa RIT No 130-2006, sobre piratería, seguida ante el tribunal del juicio oral en lo Penal de Concepción". Disponible en http://www.tribunalconstitucional.cl/wp/ver. php?id=124 [fecha de visita 8 de marzo de 2013].

- Tribunal Constitucional. 8 de abril de 2002. Rol No 346-02. "Requerimiento de inconstitucionalidad presentado por treinta y cinco señores Diputados respecto del Estatuto de Roma de la Corte Penal Internacional, adoptado en dicha ciudad el 17 de julio de 1998.” Disponible en http://www.tribunalconstitucional.cl/wp/ver. php?id=274 [fecha de visita 8 de marzo de 2013]. 